\title{
Removal of Cyclic and Linear Siloxanes in Effluents from a Cosmetic Wastewater Treatment Plant by Electrochemical Oxidation
}

\author{
Chunhui Zhang ${ }^{*}$, Minying Jin, Shihe Zhang, Zheng Li, Haoran Li
}

School of Chemical \& Environmental Engineering, China University of Mining \& Technology (Beijing), Beijing 100083, China

*E-mail: truemanjung@163.com

doi: $10.20964 / 2016.08 .04$

Received: 28 April 2016 / Accepted: 23 May 2016 / Published: 7 July 2016

The presence of cyclic and linear siloxanes in wastewater samples after different processing units of a cosmetic wastewater treatment plant (WWTP) in Beijing was investigated in the current study. Dodecamethylcyclohexasiloxane (D6) and linear siloxanes (L5 to L16) were detected in wastewater. D6, L14, L15 and L16 were the dominant siloxanes in wastewater. An electrochemical oxidation reactor was applied for advanced treatment of siloxanes in cosmetic WWTP effluents. The stainless steel plates were used as anode and cathode electrode. It concluded that the removal efficiency of siloxanes was significantly enlarged with the increasing applied current density when the reaction time was increased from 0 to $20 \mathrm{~min}$. Under the optimal reaction conditions, with reaction time of $20 \mathrm{~min}$, current density of $20 \mathrm{~mA} / \mathrm{cm}^{2}$, electrode plate distance of $1.0 \mathrm{~cm}$ and electrode plate amounts of 5 pairs, the removal efficiencies of of D6, L14, L15 and L16 were from $30.2 \%$ to $93.3 \%$.

Keywords: Cyclic siloxanes, linear siloxanes, wastewater treatment plants (WWTPs), electrochemical oxidation, persistent organic pollutants (POPs)

\section{$\underline{\text { FULLTEXT }}$}

(C) 2016 The Authors. Published by ESG (www.electrochemsci.org). This article is an open access article distributed under the terms and conditions of the Creative Commons Attribution license (http://creativecommons.org/licenses/by/4.0/). 